\title{
Simple Wireless Nurse Call on Distance Measurement
}

\author{
Wisnu Kartika ${ }^{1 *}$, Irvan Santoso ${ }^{2}$, Kuat Supriyadi ${ }^{3}$ \\ ${ }^{1,2,3}$ Department of Medical Electronics Technology, Vocational Program, Universitas Muhammadiyah Yogyakarta, \\ Yogyakarta, Indonesia \\ Email: ${ }^{1}$ wisnu2007@umy.ac.id \\ *Corresponding Author
}

\begin{abstract}
On this era, many patients go to the hospital and the clinic because the service is better than yesterday. If there are patient suffer a sickness and on the patient bed so the patient will call the nurse using a bell to call the nurse on the treatment room on the hospital. The previous research uses cable to connect the nurse room with the patient room. In this research we proposed a new scheme that is wireless nurse call. The wireless nurse call will minimize the cable. This research module using Arduino. There are consist of transmitter and receiver module. The system consists of the software and the hardware. There are one master transmitter module and four receiver module. The receiver module is tested on several place and several barriers. The visualization can be displayed on the PC (Personal Computer) or Laptop using Microsoft Visual C\# software. The visualization is included the four room notification with display and sound. From the research, this module can work well. From the research, we conclude that the module can work and can over the barrier and several far away from the master module.
\end{abstract}

Keywords-Arduino, nurse call, visual C\#, wireless

\section{INTRODUCTION}

The hospital can be filled by much patient with many kind of sickness. The patient is on several condition start from the few to hard suffer of the sickness level. The doctor and the nurse can coordinate to cover the patient illness [1][2][3]. The patient if in the accute condition usually call the nurse from the bed by clicking the bell [4][5][6][7].

The previous module uses cable to connect the master (the nurse control room) and the small module (on the patient bed side) on each treatment room [8][9][10][11][12]. From the research by Taufik Alfianur Wibowo that is the research using cable to transmit the data and the display using seven segment [13][14][15][16]. This research is improved by Sultan Al Badrul Munir, the data transmission using Bluetooth wirelessly with range up to fifteen meter [17][18][19]. But the transmitter is branched by four items so it will so close [20][21][22][23][24].

Ilham Sayekti improved this module by using Xbee to transmit data from transmitter to receiver with range up to twenty meter but there are no LCD display for this module $[25][26][27][28][29][30][31]$. The improved system by Abrory Lutfi is using cable to connect the transmitter and receiver but this system can allow voice to communicate between the nurse and the patient[32].
From the previous research, this research proposed the new scheme to cover this previous module. This module using one master and four receivers. This module using the Arduino Nano and the Visual C\# to implement this system.

This paper is consisted of four section. The first section is Introduction. The second section is System Design. The third section is the result and discussion and the last section is conclusion.

\section{SYSTEM DESIGN}

The system design contains hardware design and software design. The hardware system contains Arduino Nano, NRF24L01, and push button. The nurse call room can be displayed on the PC or Laptop with Visual C\#. The workflow of the system can be seen on the diagram in Figure 1.

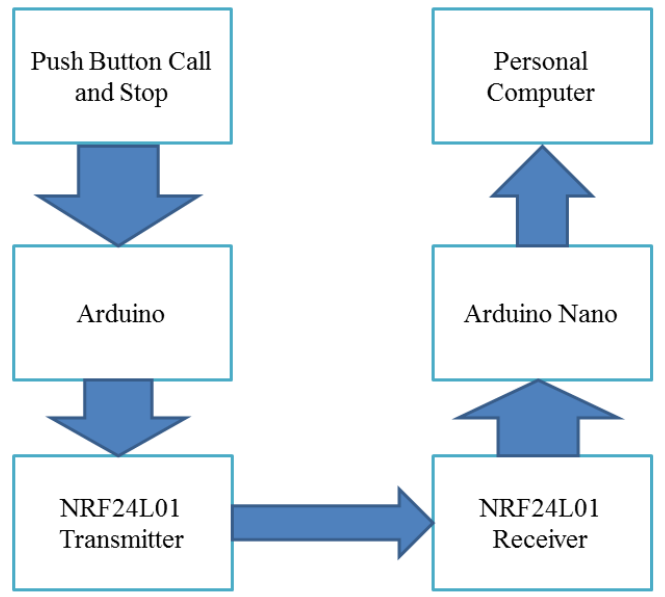

Fig. 1. The Block Diagram

The Fig. 1 shows that the module is connected to the 220 $\mathrm{V}$ AC source. The adaptor converts the $220 \mathrm{~V}$ AC to the $5 \mathrm{~V}$ DC to be connected to the microcontroller. When the push button is pressed so the analog signal will be transferred to the minimum system. This analog signal is changed to the digital signal. The digital signal will be sent by the NRF24L01 transmitter to the NRF24L01 receiver via radio frequency. This information (digital signal) will be displayed on the software designed using Visual C\#.

The software interface can be seen on the Fig. 2. The software is located on nurse control room. The software 
shows the four room notification. There are four room. If the module on the room one is clicked so this notification will be displayed on the room one on the software shown in Fig. 2.

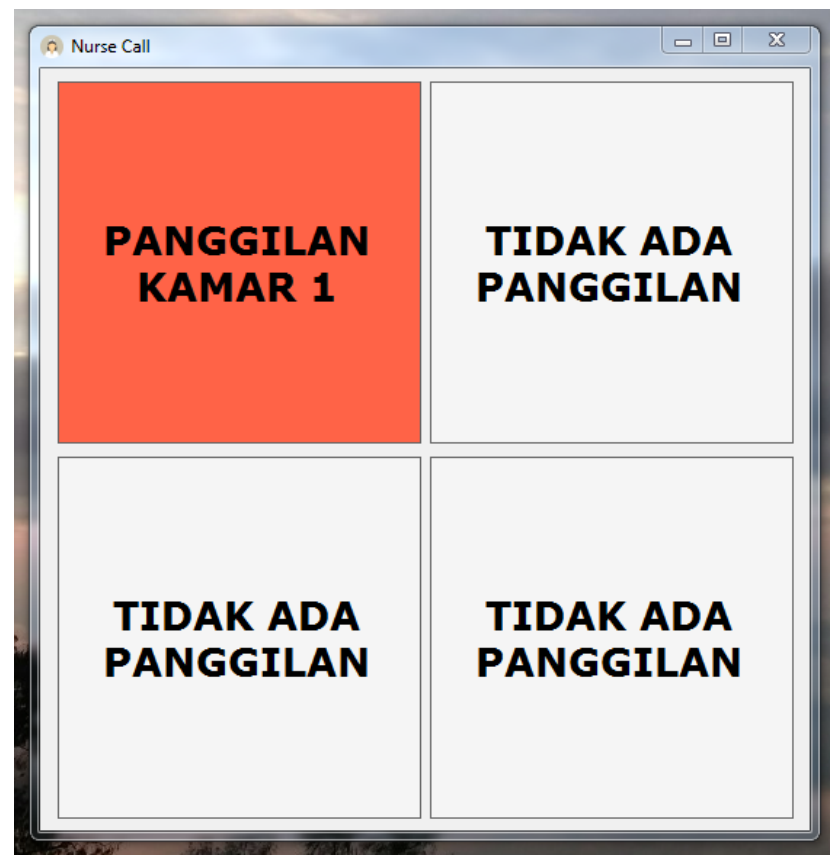

Fig. 2. The Display When Room 1 is Clicked

The research module can be seen on the Fig. 3. The device is transmitter and the receiver. The transmitter is in the patient room and the receiver is in the nurse office that connect to the computer. The opening interface in computer can be seen on the Fig. 4. The OK button is used to connect to the receiver device.

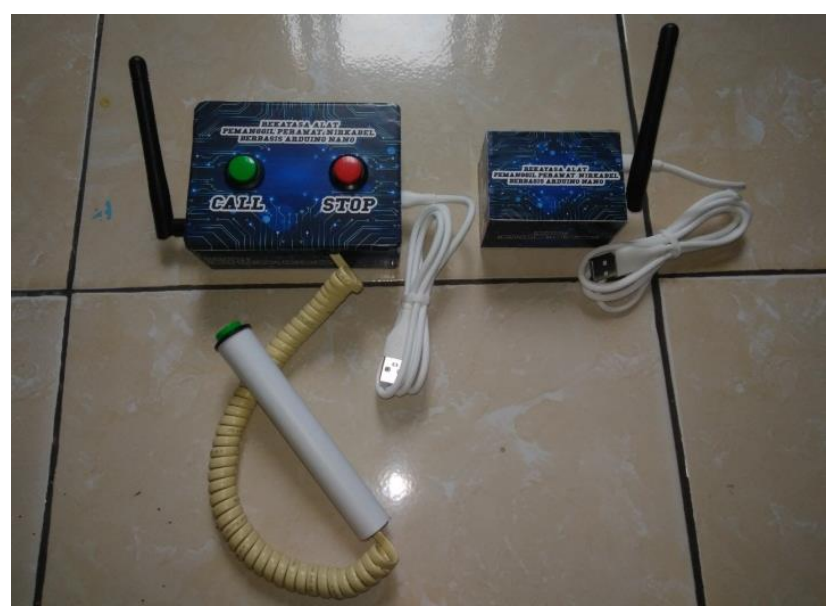

Fig. 3. The Proposed Module

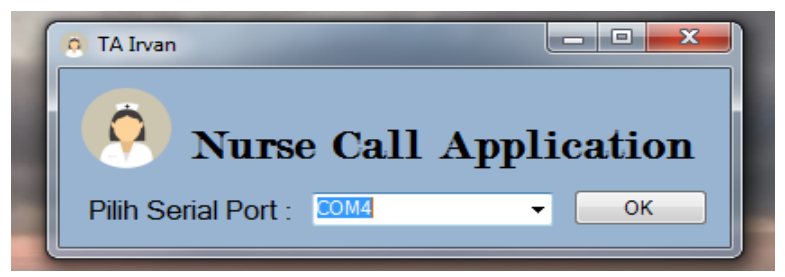

Fig. 4. The Software Opening

\section{THE RESULT AND DISCUSSION}

The module is tested by using several various of obstacle and distance. The distance will be shown on the Table I.

Table I. The Distance Measurement Testing without Obstacle

\begin{tabular}{|c|c|c|c|c|}
\hline \multirow{2}{*}{$\begin{array}{c}\begin{array}{c}\text { Distance } \\
\text { (meter) }\end{array} \\
\end{array}$} & \multicolumn{4}{|c|}{ The Condition on Data Transmission } \\
\hline & Transmitter 1 & Transmitter 2 & Transmitter 3 & Transmitter 4 \\
\hline 3 & Success & Success & Success & Success \\
\hline 5 & Success & Success & Success & Success \\
\hline 8 & Success & Success & Success & Success \\
\hline 10 & Success & Success & Success & Success \\
\hline 13 & Success & Success & Success & Success \\
\hline 15 & Success & Success & Success & Success \\
\hline 18 & Success & Success & Success & Success \\
\hline 20 & Success & Success & Success & Success \\
\hline 23 & Success & Success & Success & Success \\
\hline 25 & Success & Success & Success & Success \\
\hline 28 & Success & Success & Success & Success \\
\hline 30 & Success & Success & Success & Success \\
\hline 33 & Success & Success & Success & Success \\
\hline 35 & Success & Success & Success & Success \\
\hline 38 & Success & Success & Success & Success \\
\hline 40 & Success & Success & Success & Success \\
\hline 43 & Success & Success & Success & Success \\
\hline 45 & Success & Success & Success & Success \\
\hline 48 & Success & Success & Success & Success \\
\hline 50 & Success & Success & Success & Success \\
\hline 53 & Success & Success & Success & Success \\
\hline 55 & Failed & Failed & Failed & Failed \\
\hline
\end{tabular}

Based on the results in Table I, it can be analyzed that testing the module with a variable distance without an obstacle as much as 11 times the data collection, it is found that the farthest distance that the module can sending the data reach as far as 53 meters.

\section{CONCLUSION}

Based on the results of the research, it can be concluded that the appliance cannot work using a battery voltage source, for example using a power bank. During the test, several factors can be found that can affect the distance the device can reach that is wall material, wall thickness and networks or signals such as Wi-Fi signals that are around the module.

\section{ACKNOWLEDGMENT}

We say thankfull to our team who has support this research. Our research is supported by research grant LP3M Universitas Muhammadiyah Yogyakarta with SK number SK LP3M No. 034/PEN-LP3M/I/2020.

\section{REFERENCES}

[1] C. Vikasari, P. Purwiyanto, and G. M. Aji, "Teknologi Aplikasi Nurse Call berbasis Client Server Pada Rumah Sakit," J. Appl. INFORMATICS Comput., vol. 2, no. 2, pp. 01-08, Dec. 2018.

[2] H. I. AL-Salman and M. H. Salih, "A review Cyber of Industry 4.0 (Cyber-Physical Systems (CPS), the Internet of Things (IoT) and the Internet of Services (IoS)): Components, and Security Challenges.," J. Phys. Conf. Ser., vol. 1424, p. 012029, Dec. 2019.

[3] R. Afyenni, R. Idmayanti, Refni, I. P. Kirana, and F. Nova, "Mobile Applications for Gas Finding," IOP Conf. Ser. Mater. Sci. Eng., vol. 846 , no. $1,2020$.

[4] S. Aswin, N. Gopalakrishnan, S. Jeyender, R. G. Prasanna, and S. P. Kumar, "Design development and implementation of wireless nurse call station," Proc. - 2011 Annu. IEEE India Conf. Eng. Sustain. Solut. INDICON-2011, pp. 1-6, 2011.

[5] W. X. Zhang, Y. Wang, J. C. Zou, A. W. Cui, and G. Zou, "The 
design of wireless sensor network calling system based on ZigBee," Proc. 2017 IEEE 2nd Inf. Technol. Networking, Electron. Autom. Control Conf. ITNEC 2017, vol. 2018-Janua, pp. 625-628, 2018.

[6] S. Sendra, P. Romero-Diaz, J. Navarro-Ortiz, and J. Lloret, "Smart Infant Incubator Based on LoRa Networks," Proc. IEEE/ACS Int. Conf. Comput. Syst. Appl. AICCSA, vol. 2018-November, 2019.

[7] S. Sahoo, B. Champaty, K. Pal, S. S. Ray, and D. N. Tibarewala, "Wireless transmission of alarm signals from baby incubators to neonatal nursing station," 1st Int. Conf. Autom. Control. Energy Syst. - 2014, ACES 2014, pp. 1-5, 2014

[8] J. Klemets, T. E. Evjemo, and L. Kristiansen, "Designing for redundancy: Nurses experiences with the wireless nurse call system," Stud. Health Technol. Inform., vol. 192, no. 1-2, pp. 328332, 2013

[9] M. Ali, M. Abdelwahab, S. Awadekreim, and S. Abdalla, "Development of a Monitoring and Control System of Infant Incubator," 2018 Int. Conf. Comput. Control. Electr. Electron. Eng. ICCCEEE 2018, no. Lcd, pp. 1-4, 2018.

[10] I. Baccouche, S. Jemmali, B. Manai, R. Chaibi, and N. E. Ben Amara, "Hardware implementation of an algorithm based on kalman filtrer for monitoring low capacity Li-ion batteries," IREC 2016 - 7th Int. Renew. Energy Congr., 2016.

[11] J. Jorge et al., "Non-Contact Monitoring of Respiration in the Neonatal Intensive Care Unit," Proc. - 12th IEEE Int. Conf. Autom. Face Gesture Recognition, FG 2017 - 1st Int. Work. Adapt. Shot Learn. Gesture Underst. Prod. ASLAGUP 2017, Biometrics Wild, Bwild 2017, Heterog. Face Recognition, HFR 2017, Jt. Chall. Domin. Complement. Emot. Recognit. Using Micro Emot. Featur. Head-Pose Estim. DCER HPE 2017 3rd Facial Expr. Recognit. Anal. Challenge, FERA 2017, pp. 286-293, 2017.

[12] R. Y. Endra, A. Cucus, and F. N. Affandi, "The Concept and Implementation of Smart Room using Internet of things (IoT) for Cost Efficiency and Room Security," J. Phys. Conf. Ser., vol. 1381, no. $1,2019$.

[13] L. Kristiansen, "Nurse calls via personal wireless devices; some challenges and possible design solutions," Proc. - IEEE Symp. Comput. Med. Syst., no. 7491, pp. 1-6, 2011.

[14] S. Aulia, P. Maria, A. A. Asri, and R. Dewi, "The Implementation of Sound Output Image Processing with Wireless Based on Control to Vehicle Identification," IOP Conf. Ser. Mater. Sci. Eng., vol. 846, no. $1,2020$.

[15] Suryadi, M. Zuradi, T. Angraini, and L. Devy, "Implementation of Wireless Sensor Network for Four sensors on Natural Disaster Early Warning System," IOP Conf. Ser. Mater. Sci. Eng., vol. 846, no. 1, 2020.

[16] Yuhefizar, A. Nasution, R. Putra, E. Asri, and D. Satria, "IoT: Heart Rate Monitoring Tool Using Android with Alert Messanger Telegram System,” IOP Conf. Ser. Mater. Sci. Eng., vol. 846, no. 1, 2020 .

[17] W. Riyanto, D. Irawan, T. J. W. Adi, D. Iranata, and A. Rizki Amalia, "Structural Performance Monitoring System Using Android RViSITS for High Rise Building," J. Phys. Conf. Ser., vol. 1381, no. $1,2019$.

[18] S. Suhanto, F. Faizah, and K. Kustori, "Designing a building automation system with open protocol communication and intelligent electronic devices," J. Phys. Conf. Ser., vol. 1381, no. 1, 2019.

[19] P. Sulistyowati, D. W. Utomo, J. R. Batlolona, A. Saregar, M. N. Hudha, and A. C. Yusro, "Practicing Energy Saving Habits of Elementary Students Through Development of Lectora Inspire Software Based Instructional Media," J. Phys. Conf. Ser., vol. 1381, no. $1,2019$.

[20] P. G. Septian et al., "RANCANG BANGUN SMART NURSE CALL ( PEMANGGIL PERAWAT )," J. JARTEL, vol. 8, no. 1, pp. 128-134, 2019.

[21] N. H. Wijaya, Budimansyah, and D. Sukwono, "Wireless X-ray Machine Control Based on Arduino with Kv Parameters," J. Phys. Conf. Ser., vol. 1430, p. 012040, Jan. 2020.

[22] E. Loniza, S. A. Fasai, S. Bariton, and N. Rughaisyiah, "Dosimeter Co-Card Alarm X-ray Radiation Dosage Monitoring Instrument," $J$. Phys. Conf. Ser., vol. 1471, p. 012041, Feb. 2020.

[23] S. Budilaksono et al., "Designing an Ultrasonic Sensor Stick Prototype for Blind People," J. Phys. Conf. Ser., vol. 1471, no. 1, p. 012020, Feb. 2020.

[24] E. Maiyana, M. Susanti, Supratman, Y. Tria, and Ramdalel, "Application of Android System for Anti-Drug Information," $J$. Phys. Conf. Ser., vol. 1471, p. 012001, Feb. 2020.

[25] Ilham Sayekti, "Bel Pemanggil Perawat Berbasis Wireless Menggunakan Xbee,” J. Tek. Elektro Terap., p. 174, 2013.

[26] R. Ponte, V. Giagka, and W. A. Serdijn, "Design and Custom Fabrication of a Smart Temperature Sensor for an Organ-on-a-chip Platform," 2018 IEEE Biomed. Circuits Syst. Conf. BioCAS 2018 Proc., no. C, pp. 1-4, 2018.

[27] Z. Zamrudi, S. Karim, M. Faridha, D. Maharani, and A. Dewi Kuraesin, "Smart meter adoption: The role of consumer experience in using smart device," J. Phys. Conf. Ser., vol. 1175, no. 1, 2019.

[28] D. Satria, Zulfan, Munawir, and T. Hidayat, "Implementation of wireless sensor network (WSN) on garbage transport warning information system using GSM module," J. Phys. Conf. Ser., vol. 1175 , no. $1,2019$.

[29] Y. Mukhlis, E. Triawati, and V. Ernita, "Design System on Chip PreAmp Embedded on Electrocardiograph Based 0,35 CMOS Technology," J. Phys. Conf. Ser., vol. 1175, no. 1, pp. 0-9, 2019.

[30] M. Mustari Syafiq Ismail et al., "IoT Based Smart Parking System," J. Phys. Conf. Ser., vol. 1424, p. 012021, Dec. 2019.

[31] N. Yasmin Khairani Zakaria, H. Zaini, S. Siraj, M. Md Yunus, and H. Hashim, "Learning of Medicinal Herbs Using QR Codes," $J$. Phys. Conf. Ser., vol. 1424, p. 012049, Dec. 2019.

[32] P. Limprasitwong and C. Thongchaisuratkrul, "Plant Growth Using Automatic Control System under LED, Grow, and Natural Light," ICAICTA 2018 - 5th Int. Conf. Adv. Informatics Concepts Theory Appl., pp. 192-195, 2018. 